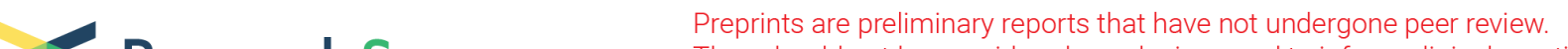 Research Square
or referenced by the media as validated information.
}

\section{Benchmark examination of blood amino acids patterns in phenylketonuric neonates and young children on phenylalanine-restricted dietary treatment}

\section{Zhihui Wan}

Capital Medical University Beijing Obstetrics and Gynecology Hospital

\section{Eric Rosenbaum}

Arkansas Children s Hospital

Wei Liu

Capital Medical University Beijing Obstetrics and Gynecology Hospital

\section{Boyan Song}

Capital Medical University Beijing Obstetrics and Gynecology Hospital

\section{Xiaofei Yue}

Capital Medical University Beijing Obstetrics and Gynecology Hospital

\section{Yuanyuan Kong}

Capital Medical University Beijing Obstetrics and Gynecology Hospital

\section{Tianhe Li}

Capital Medical University Beijing Obstetrics and Gynecology Hospital

\section{Yanhong Zhai}

Capital Medical University Beijing Obstetrics and Gynecology Hospital

Zhijun Ma ( $D$ masu7162000@hotmail.com )

Capital Medical University Beijing Obstetrics and Gynecology Hospital

\section{Zheng Cao ( $\sim$ zhengcao2011@hotmail.com )}

Capital Medical University Beijing Obstetrics and Gynecology Hospital https://orcid.org/0000-00020968-1864

\section{Research article}

Keywords: Phenylketonuria, blood amino acid patterns, liquid chromatography-tandem mass spectrometry

Posted Date: May 26th, 2020

DOl: https://doi.org/10.21203/rs.3.rs-29788/v1 
License: (c) (i) This work is licensed under a Creative Commons Attribution 4.0 International License. Read Full License 


\section{Abstract \\ Background}

Phe-restricted diets have been the basis of therapy for phenylketonurics; however, little is known how this treatment effects homeostasis of other important amino acids. This study aimed to describe blood amino acid patterns in neonates with phenylketonuria (PKU) and identify any effects of Phe restriction on these patterns in young children.

\section{Methods}

Neonate group (age 0-4 weeks): 45 PKU patients, 45 age-/sex-matched controls without PKU; 1-4 yearold group: 27 diet-treated PKU patients, 27 age-/sex-matched children without PKU. Concentrations of 11 amino acids were measured using liquid chromatography-tandem mass spectrometry (LC-MS/MS) performed on dried blood spots.

\section{Results}

Elevated blood phenylalanine (Phe), arginine (Arg), citrulline (Cit), valine (Val) and methionine (Met) concentrations were observed in PKU neonates relative to controls (Phe, Arg, Cit, Val: $P<0.001$; Met: $P<$ 0.05), of which Phe, Arg, and Met levels could be either partially or completely restored with dietary intervention. Diet had no effect on elevated Cit and Val. Decreased blood tyrosine (Tyr) and proline (Pro) concentrations were observed in PKU neonates compared to controls $(P<0.001)$. Both amino acids could be near completely restored to normal with dietary treatment. No significant differences in alanine (Ala), leucine (Leu), ornithine (Orn) and glycine (Gly) concentrations were found in the PKU neonates and 1-4 year-old groups $(P>0.05)$.

\section{Conclusions}

Blood amino acid homeostasis is disrupted in neonates and young children with PKU. Although dietary intervention adjusts amino acid homeostasis in the direction of a healthy equilibrium, complete restoration is not achieved. This persistent disruption may represent a clinically significant barrier to achieving the best possible therapy for those with PKU. Use of laboratory technologies such as LCMS/MS enable characterization of persistent blood amino acid disequilibrium in the treated phenylketonuric. Testing of this kind presents opportunity for customized treatment feedback that may allow even greater optimization of therapy for neonates and children with PKU.

\section{Background}


Classic phenylketonuria (PKU) is an autosomal recessive disease caused by mutations in the $P A H$ gene leading to very low to near absence of the hepatic enzyme phenylalanine hydroxylase (PAH). As PAH catalyzes conversion of the essential amino acid phenylalanine (Phe) to tyrosine (Tyr) (1-4), insufficient PAH function results in an accumulation of Phe and Phe metabolites in blood that are toxic to the brain $(5,6)$. Untreated PKU patients present clinically with severe impairment in cognitive function, behavioral disorders, seizure, and lesser non-neurological sequelae (4, 7-9). In China and the United States, neonatal testing for PKU is required as part of the Chinese national and all U.S. state newborn screening programs. Treatment of classic PKU is immediate switch to a Phe-restricted diet (10).

The aim of dietary treatment is to prevent toxic hyperphenylalaninemia, usually achieved by combining strict control of natural protein intake with administration of a Phe-free or low-Phe protein diet. Efficacy of the diet is monitored with regular laboratory measurements of blood Phe concentration. European guidelines for blood Phe concentration as established by van Spronsen, et al. (2017) (11) are 120$360 \mu \mathrm{mol} / \mathrm{L}$ for those $0-12$ years or pregnant, and $120-600 \mu \mathrm{mol} / \mathrm{L}$ for those $>12$ years. U.S. guidelines, as set forth by the American College of Medical Genetics and Genomics Therapeutics Committee, establish target Phe concentration in the range of $120-360 \mu \mathrm{mol} / \mathrm{L}$ for all patients, regardless of age and pregnancy status (12).

Despite thorough understanding of the biochemical defect underlying PKU, the pathophysiology behind cognitive dysfunction and neurological impairments remains elusive (13). What is known is that high plasma concentrations of Phe influence blood-brain barrier transport of large neutral amino acids (LNAA) $(8,14,15)$. When blood Phe concentrations are elevated, Phe is preferentially transported across the blood-brain barrier at the expense of other LNAA. This results in abnormally high cerebral concentrations of Phe and abnormally low cerebral concentrations of other LNAA (i.e. tyrosine, tryptophan, valine, isoleucine, leucine, threonine, methionine and histidine) (16). Insufficient LNAA in brain tissue could lead to impaired protein synthesis essential for cognitive function, so apart from the neurotoxicity of Phe, deficiency of cerebral LNAA may also be an important factor affecting cognitive function (15). Finally, the high plasma concentrations of Phe that disrupt normal levels of brain LNAA may also lead to disequilibria in blood LNAA concentrations. Whether this disturbance in blood LNAA and symptoms of PKU are related remains the subject of further investigation.

Most PKU studies addressing blood amino acid profiles have focused on Phe and its hydroxylated relative Tyr, leaving patterns of other important amino acids insufficiently characterized. To examine the non-Phe/non-Tyr amino acids, blood concentrations of the 11 amino acids included in the commercially available PerkinElmer ${ }^{\circledR}$ NeoBase ${ }^{\mathrm{TM}}$ non-derivatized MS/MS kit were measured in PKU neonates and PKUtreated 1-4 year-olds. Concentrations were compared with those measured in normal control groups in this study using an LC-MS/MS method.

\section{Methods}


Patient data were obtained from the Beijing Newborn Screening Center (Beijing, China). The neonate group (age 0-4 weeks) consisted of 90 subjects, 45 PKU patients ( 17 female, 28 male) not yet on treatment and 45 sex-matched normal neonates. The 1-4 year-old group consisted of 54 subjects, 27 PKU patients (9 female, 18 male) on a diet control program and 27 age- and sex-matched normal subjects.

PKU neonates were identified through routine newborn screening performed using a standard dried blood spot (DBS) obtained by heel puncture. Phe concentrations above $120 \mu \mathrm{mol} / \mathrm{L}$ were considered abnormal requiring reflex testing by a combined PCR-Multiplex Ligation-dependent Probe Amplification (MLPA®) assay (SALSA® MLPA® Probemix P055-D1 PAH, MRC Holland, BV, Amsterdam, Netherlands).

PKU-treated 1-4 year-olds were on Phe-restricted dietary therapy that was initiated during the neonatal period immediately upon diagnosis. All PKU patients were examined regularly to ensure Phe concentrations were maintained within the recommended range.

\section{Ethical statement}

This study included data on PKU screening within the screening network in Beijing. Newborn screening is carried out strictly in accordance with the "Technical Specifications for Newborn Screening" issued by China's National Health Commission in 2010. This study was approved by the Ethical Committee of Beijing Obstetrics and Gynecology Hospital. Informed consents were obtained from all individuals' guardians included in this study. The research related to human use complied with all the relevant national regulations, institutional policies and is in accordance with the tenets of the Helsinki Declaration, and has been approved by the Beijing Municipal Health Commission.

\section{Sample collection and amino acid analyses}

Blood amino acid concentrations were measured from $3 \mathrm{~mm}$ punches obtained from DBS specimens collected on filter paper using high-performance liquid chromatography-tandem mass spectrometry (HPLC-MS/MS). Each punch was placed in a single well of a 96-well polypropylene microtiter plate to which $100 \mu \mathrm{L}$ of extraction solution was added to each well. The plate was sealed and agitated at $45^{\circ} \mathrm{C}$ for 45 minutes using a TriNEST ${ }^{\mathrm{TM}}$ incubator microplate shaker (PerkinElmer, Inc. Shanghai, China) set at $400 \mathrm{rpm}$. Finally, $80 \mu \mathrm{L}$ of extract from each specimen was transferred to a new $96-w e l l$ plate. The plate was sealed and then analyzed using LC-MS/MS. LC-MS/MS employed a HPLC component consisting of a Waters ${ }^{\circledR} 1525$ micro HPLC pump coupled to a Waters ${ }^{\circledR}$ ACQUITY TQD tandem quadrupole mass spectrometer system (Waters ${ }^{\circledR}$ Technologies Shanghai, Ltd., Shanghai, China). Sample preparation and injection were performed using a Waters ${ }^{\circledR} 2777 C$ Sample Manager $X Y Z$ autosampler robot. The PerkinElmer ${ }^{\circledR} \mathrm{NeoBase}^{\mathrm{TM}}$ non-derivatized MS/MS kit (PerkinElmer, Inc. Shanghai, China) was used to measure concentrations of the 11 on-panel amino acids. Data acquisition for amino acid pattern analyses was performed by LC-MS/MS quantification of the 11 on-panel PerkinElmer ${ }^{\circledR}$ NeoBase $^{\mathrm{TM}}$ amino 
acids-alanine (Ala), arginine (Arg), citrulline (Cit), glycine (Gly), leucine (Leu), methionine (Met), ornithine (Orn), Phe, proline (Pro), Tyr, and valine (Val).

\section{Statistical analysis}

Statistical analyses were performed using SPSS ${ }^{\circledR}$ Statistics V22.0 software (IBM, Corp., Armonk, NY, USA). Mean concentrations of each amino acid were calculated for all study cohorts and presented in the unit of $\mu \mathrm{mol} / \mathrm{L} \pm$ standard error of mean (SEM). Group means were compared using two-tailed Student's ttests.

\section{Results}

Comparing PKU neonates with age-/sex-matched controls, the following blood amino acids were increased in the PKU group: Phe $(P<0.001)$, Arg $(P<0.001)$, Cit $(P<0.001)$, Val $(P=0.001)$ and Met $(P=$ $0.03)$. Amino acids that showed decreased blood concentration in PKU neonates were $\operatorname{Tyr}(P<0.001)$ and Pro $(P<0.001$; Table 1). Of note, in the PKU 1-4 year-old group receiving dietary treatment, the relative concentrations of Cit and Val were not significantly different from relative concentrations in the PKU neonate group (presented as the ratio of amino acid concentration in PKU 1-4 year-olds to age-/sexmatched normal controls; Figure 1).

By contrast, statistically significant differences in relative concentrations of Arg, Tyr, Pro and Met were observed when compared with the PKU neonate group (Figure 1). Blood concentration of Arg, Tyr, Pro, and Met were completely restored by dietary treatment in the 1-4 year-olds with PKU, showing no statistically significant difference from normal age-/sex-matched controls (Table 2). As expected, although the relative decrease in Phe blood concentration in the diet-treated 1-4 year-olds was the most prominent of all amino acids tested (Figure 1), the absolute concentration of Phe in PKU 1-4 year-olds was still 6 times higher than that observed in normal children, $332.5 \mu \mathrm{mol} / \mathrm{L} \mathrm{vs.} 55.0 \mu \mathrm{mol} / \mathrm{L}$, respectively (Table 2), suggesting limited efficacy of standard dietary treatment in normalizing Phe levels. There was no difference in concentration of the 11 on-panel amino acids among female and male subjects in any of the study cohorts. Blood amino acid concentrations in neonates and 1-4 year-olds with and without PKU are summarized in Tables 1 and 2, respectively.

\section{Discussion}

Although current dietary treatment of PKU has been successful in curtailing disability, important questions remain surrounding details of these effects. Some of these include 1) dietary compliance due to unpalatability, 2) persistence of significant neurological and/or psychosocial abnormalities despite early intervention, and 3 ) potential nutritional deficiencies resulting from a restrictive diet (7). Long term studies may lead to a better understanding of the lifelong additive effects of Phe-restricted dietary 
treatment. In this study, we investigated blood amino acid patterns in PKU neonates and PKU-treated children compared to age-/sex-matched controls.

The results of this study demonstrated abnormal blood amino acid homeostasis in PKU neonates that would not completely normalize into childhood despite dietary intervention. Elevated blood Phe concentration in PKU neonates was partially restored by Phe-restricted dietary treatment with mean blood Phe being significantly higher in the PKU 1-4 year-old group compared to age-/sex-matched controls. In addition to our study, other smaller studies have examined aspects of amino acid homeostasis in phenylketonurics. Huemer et al. (17) followed 16 children with PKU who received insufficient dietary intervention demonstrating that Arg concentration was not significantly different from normal controls. This finding was consistent with our data in which mean blood Arg concentration in the treated-PKU 1-4 year-olds returned to a normal level. The elevated mean blood Arg concentration we observed in PKU neonates may be associated with increased oxidative stress seen in this population $(17,18)$. Our findings show that Phe-restricted dietary therapy is able to rescue increased Arg levels in PKU neonates, though the exact mechanism is not yet understood.

As previously reported (17), asymmetric dimethylarginine (ADMA) and homocysteine (Hcy) were lower in PKU treated 1-4 year-olds compared to controls. While Hcy post-translationally inhibits dimethylarginine dimethylaminohydrolase (DDAH) activity (19), an enzyme responsible for conversion of ADMA to Cit, it is hypothesized that low levels of Hcy may enhance DDAH activity (19) and synthesis of Cit. Consistent with this hypothesis, we observed in our study that blood Cit levels were significantly higher in both PKU neonates and 1-4 year-olds under treatment compared to normal controls. Similarly, significantly higher concentrations of Val were observed in both PKU neonates and PKU-treated 1-4 year-olds. Taken together, it appears that Phe-restricted dietary treatment is not effective in bringing Cit and Val blood concentrations back to normal levels.

Our findings also revealed that the decreased Tyr and Pro concentrations and the increased Met concentration observed in PKU neonates caused by PAH deficiency could be completely restored by dietary treatment. We also found that blood concentrations of Ala, Leu, Orn, and Gly in our phenylketonuric cohorts are similar to those in normal controls, suggesting that both PAH deficiency and Phe-restricted dietary therapy have little to no effect on blood concentration of these amino acids.

\section{Conclusions}

In this study, we conducted the first comprehensive analysis characterizing blood amino acid patterns in PKU neonates and PKU-treated 1-4 year-olds compared to age-/sex-matched controls. Amino acid homeostasis is disrupted in PKU neonates and certain amino acid blood concentrations are able to be partially or completely restored with dietary treatment; however, normalization of blood amino acid concentrations was never completely achieved. Our findings establish need for further investigation aimed at delineating the effects of this failure to normalize with standard dietary therapy and whether adjustments and/or supplemental treatment for phenylketonurics is clinically indicated. 


\section{Abbreviations}

PKU: Phenylketonuria

LNAA: Large neutral amino acids

LC-MS/MS: Liquid chromatography-tandem mass spectrometry

PAH: Phenylalanine hydroxylase

DBS: Dried blood spot

Ala: Alanine

Arg: Arginine

Cit: Citrulline

Gly: Glycine

Leu: Leucine

Met: Methionine

Orn: Ornithine

Phe: Phenylalanine

Pro: Proline

Tyr: Tyrosine

Val: Valine

\section{Declarations}

Ethics approval and consent to participate

This study was approved by the Ethics Committee of Beijing Obstetrics and Gynecology Hospital.

Consent for publication

Not applicable.

\section{Availability of data and materials}

All data generated or analyzed during this study are included in this published article. 


\section{Competing interests}

The authors declare no conflict of interest.

\section{Funding}

This study was supported by grants from the National Natural Science Foundation of China (31700881).

\section{Authors' contributions}

ZW, ER, ZM and ZC: statistics, drafting of the article. WL, BS, XY, YK, TL and YZ: data collection. ZW, ZM and ZC: concept/design, data interpretation, approval of article. Read and approval of the final manuscript: all authors.

\section{Acknowledgements}

Not applicable.

\section{References}

1. Camp KM, Parisi MA, Acosta PB, Berry GT, Bilder DA, Blau N, et al. Phenylketonuria Scientific Review Conference: state of the science and future research needs. Mol Genet Metab. 2014;112(2):87-122.

2. Jervis GA. Phenylpyruvic oligophrenia deficiency of phenylalanine-oxidizing system. Proc Soc Exp Biol Med. 1953;82(3):514-5.

3. Scriver CR. The PAH gene, phenylketonuria, and a paradigm shift. Hum Mutat. 2007;28(9):831-45.

4. Blau N, van Spronsen FJ, Levy HL. Phenylketonuria. Lancet. 2010;376(9750):1417-27.

5. Elsas LJ, Greto J, Wierenga A. The effect of blood phenylalanine concentration on Kuvan response in phenylketonuria. Mol Genet Metab. 2011;102(4):407-12.

6. Demirkol M, Gizewska M, Giovannini M, Walter J. Follow up of phenylketonuria patients. Mol Genet Metab. 2011;104 Suppl:S31-9.

7. Al Hafid N, Christodoulou J. Phenylketonuria: a review of current and future treatments. Transl Pediatr. 2015;4(4):304-17.

8. van Vliet D, Bruinenberg VM, Mazzola PN, van Faassen MH, de Blaauw P, Pascucci T, et al. Therapeutic brain modulation with targeted large neutral amino acid supplements in the Pah-enu2 phenylketonuria mouse model. Am J Clin Nutr. 2016;104(5):1292-300.

9. Gonzalez MJ, Gutierrez AP, Gassio R, Fuste ME, Vilaseca MA, Campistol J. Neurological complications and behavioral problems in patients with phenylketonuria in a follow-up unit. Mol Genet Metab. 2011;104 Suppl:S73-9.

10. MacDonald A, Rocha JC, van Rijn M, Feillet F. Nutrition in phenylketonuria. Mol Genet Metab. 2011;104 Suppl:S10-8. 
11. van Spronsen FJ, van Wegberg AM, Ahring K, Belanger-Quintana A, Blau N, Bosch AM, et al. Key European guidelines for the diagnosis and management of patients with phenylketonuria. Lancet Diabetes Endocrinol. 2017;5(9):743-56.

12. Vockley J, Andersson HC, Antshel KM, Braverman NE, Burton BK, Frazier DM, et al. Phenylalanine hydroxylase deficiency: diagnosis and management guideline. Genet Med. 2014;16(2):188-200.

13. Imperlini E, Orru S, Corbo C, Daniele A, Salvatore F. Altered brain protein expression profiles are associated with molecular neurological dysfunction in the PKU mouse model. J Neurochem. 2014;129(6):1002-12.

14. Smith QR. Transport of glutamate and other amino acids at the blood-brain barrier. J Nutr. 2000;130(4S Suppl):1016S-22S.

15. van Spronsen FJ, Hoeksma M, Reijngoud DJ. Brain dysfunction in phenylketonuria: is phenylalanine toxicity the only possible cause? J Inherit Metab Dis. 2009;32(1):46-51.

16. Pratt OE. A new approach to the treatment of phenylketonuria. J Ment Defic Res. 1980;24(3):203-17.

17. Huemer M, Simma B, Mayr D, Moslinger D, Muhl A, Schmid I, et al. Free asymmetric dimethylarginine (ADMA) is low in children and adolescents with classical phenylketonuria (PKU). J Inherit Metab Dis. 2012;35(5):817-21.

18. Kumru B, Kaplan DS, Ozturk Hismi B, Celik H. Effect of Blood Phenylalanine Levels on Oxidative Stress in Classical Phenylketonuric Patients. Cell Mol Neurobiol. 2018;38(5):1033-8.

19. Stuhlinger MC, Tsao PS, Her JH, Kimoto M, Balint RF, Cooke JP. Homocysteine impairs the nitric oxide synthase pathway: role of asymmetric dimethylarginine. Circulation. 2001;104(21):2569-75.

\section{Tables}

Table 1 Mean blood amino acid concentrations in neonates with or without PKU 


\begin{tabular}{|c|c|c|c|c|c|c|c|c|c|}
\hline \multirow{2}{*}{$\begin{array}{r}\text { Amino acid } \\
(\mu \mathrm{mol} / \mathrm{L})\end{array}$} & \multicolumn{4}{|c|}{ PKU neonates just diagnosed } & \multicolumn{4}{|c|}{ normal neonates } & \multirow[t]{2}{*}{$p$ value $^{\mathrm{c}}$} \\
\hline & total $(n=45)$ & $\begin{array}{c}\text { females } \\
(\mathrm{n}=17)\end{array}$ & $\begin{array}{l}\text { males } \\
(n=28)\end{array}$ & $p$ value $^{\mathrm{a}}$ & $\begin{array}{c}\text { total } \\
(n=45)\end{array}$ & $\begin{array}{c}\text { females } \\
(\mathrm{n}=17)\end{array}$ & $\begin{array}{c}\text { males } \\
(n=28)\end{array}$ & $p$ value $^{\mathrm{b}}$ & \\
\hline Phe & $\begin{array}{c}1231.0 \pm \\
116.3\end{array}$ & $\begin{array}{c}1104.3 \pm \\
194.1\end{array}$ & $\begin{array}{c}1307.6 \pm \\
146.0\end{array}$ & 0.40 & $52.3 \pm 1.4$ & $52.1 \pm 1.7$ & $53.0 \pm 1.3$ & 0.66 & $<0.001$ \\
\hline Arg & $28.3 \pm 1.9$ & $32.2 \pm 3.7$ & $26.0 \pm 2.0$ & 0.12 & $18.7 \pm 1.2$ & $18.2 \pm 1.0$ & $20.2 \pm 1.3$ & 0.07 & $<0.001$ \\
\hline Cit & $25.1 \pm 1.1$ & $25.4 \pm 1.5$ & $25.0 \pm 1.4$ & 0.86 & $16.1 \pm 0.6$ & $16.3 \pm 0.7$ & $16.6 \pm 0.6$ & 0.74 & $<0.001$ \\
\hline Val & $182.6 \pm 7.2$ & $197.6 \pm 11.3$ & $173.5 \pm 9.1$ & 0.11 & $\begin{array}{c}151.2 \pm \\
6.0\end{array}$ & $150.1 \pm 6.3$ & $\begin{array}{c}153.3 \pm \\
5.4\end{array}$ & 0.70 & 0.001 \\
\hline Tyr & $94.2 \pm 5.4$ & $106.1 \pm 9.0$ & $85.1 \pm 5.7$ & 0.06 & $\begin{array}{c}144.8 \pm \\
9.9\end{array}$ & $151.7 \pm 11.8$ & $\begin{array}{c}139.0 \pm \\
6.3\end{array}$ & 0.31 & $<0.001$ \\
\hline Pro & $167.5 \pm 6.5$ & $180.5 \pm 9.2$ & $159.7 \pm 8.5$ & 0.12 & $\begin{array}{c}213.3 \pm \\
10.5\end{array}$ & $200.1 \pm 9.1$ & $\begin{array}{c}212.6 \pm \\
10.1\end{array}$ & 0.38 & $<0.001$ \\
\hline Met & $28.3 \pm 1.0$ & $29.9 \pm 2.0$ & $27.4 \pm 1.1$ & 0.25 & $25.5 \pm 0.8$ & $26.0 \pm 1.0$ & $26.2 \pm 0.6$ & 0.82 & 0.03 \\
\hline Ala & $\begin{array}{c}309.3 \pm \\
15.5\end{array}$ & $341.2 \pm 27.8$ & $289.9 \pm 17.8$ & 0.11 & $\begin{array}{c}348.7 \pm \\
13.4\end{array}$ & $338.2 \pm 13.2$ & $\begin{array}{c}340.6 \pm \\
13.2\end{array}$ & 0.90 & 0.06 \\
\hline Leu & $204.3 \pm 8.1$ & $223.2 \pm 13.5$ & $192.8 \pm 9.6$ & 0.07 & $\begin{array}{c}184.7 \pm \\
7.3\end{array}$ & $179.7 \pm 7.7$ & $\begin{array}{c}183.1 \pm \\
6.8\end{array}$ & 0.74 & 0.08 \\
\hline Orn & $\begin{array}{c}169.0 \pm \\
11.6\end{array}$ & $184.1 \pm 15.8$ & $159.8 \pm 16.0$ & 0.32 & $\begin{array}{c}144.9 \pm \\
7.3\end{array}$ & $135.2 \pm 7.2$ & $\begin{array}{c}145.8 \pm \\
6.8\end{array}$ & 0.29 & 0.08 \\
\hline Gly & $\begin{array}{c}402.0 \pm \\
25.8\end{array}$ & $414.9 \pm 42.1$ & $394.2 \pm 33.1$ & 0.70 & $\begin{array}{c}395.0 \pm \\
14.7\end{array}$ & $399.8 \pm 16.4$ & $\begin{array}{c}423.4 \pm \\
16.1\end{array}$ & 0.32 & 0.81 \\
\hline
\end{tabular}

a: $p$ value from the comparison between PKU neonates females and males.

$\mathrm{b}: p$ value from the comparison between normal neonates females and

males.

c: $\mathrm{p}$ value from the comparison between PKU neotates (total) and normal neotnates (total).

The data in Table 1 were presented as mean \pm standard

deviation.

Table 2 Mean blood amino acid concentrations in children with or without PKU 


\begin{tabular}{|c|c|c|c|c|c|c|c|c|c|}
\hline \multirow{2}{*}{$\begin{array}{c}\text { Amino acid } \\
(\mu \mathrm{mol} / \mathrm{L})\end{array}$} & \multicolumn{4}{|c|}{ PKU children with treatment } & \multicolumn{4}{|c|}{ normal children } & \multirow[t]{2}{*}{$p$ value } \\
\hline & $\begin{array}{c}\text { total } \\
(\mathrm{n}=27)\end{array}$ & $\begin{array}{c}\text { females } \\
(n=9)\end{array}$ & $\begin{array}{c}\text { males } \\
(\mathrm{n}=18)\end{array}$ & $p$ value $^{a}$ & $\begin{array}{l}\text { total } \\
(n=27)\end{array}$ & $\begin{array}{c}\text { females } \\
(n=9)\end{array}$ & $\begin{array}{c}\text { males } \\
(\mathrm{n}=18)\end{array}$ & $p$ value $^{\mathrm{b}}$ & \\
\hline Phe & $\begin{array}{c}332.5 \pm \\
29.6\end{array}$ & $374.6 \pm 61.3$ & $\begin{array}{c}311.5 \pm \\
32.3\end{array}$ & 0.32 & $55.0 \pm 2.1$ & $53.6 \pm 3.8$ & $55.7 \pm 2.5$ & 0.64 & $<0.001$ \\
\hline Arg & $30.8 \pm 3.8$ & $36.5 \pm 6.0$ & $27.9 \pm 4.7$ & 0.29 & $35.0 \pm 2.3$ & $37.7 \pm 3.7$ & $33.7 \pm 2.9$ & 0.41 & 0.35 \\
\hline Cit & $44.1 \pm 3.5$ & $47.1 \pm 6.3$ & $42.6 \pm 4.3$ & 0.55 & $26.8 \pm 0.9$ & $28.1 \pm 1.7$ & $26.2 \pm 1.0$ & 0.30 & $<0.001$ \\
\hline Val & $\begin{array}{c}226.8 \pm \\
13.8\end{array}$ & $264.2 \pm 29.9$ & $\begin{array}{c}208.0 \pm \\
12.8\end{array}$ & 0.06 & $\begin{array}{c}179.0 \pm \\
6.4\end{array}$ & $\begin{array}{c}186.8 \pm \\
12.7\end{array}$ & $175.1 \pm 6.8$ & 0.38 & 0.003 \\
\hline Tyr & $77.7 \pm 5.5$ & $88.4 \pm 7.0$ & $72.4 \pm 7.3$ & 0.18 & $71.6 \pm 3.7$ & $70.5 \pm 6.6$ & $72.2 \pm 4.4$ & 0.82 & 0.37 \\
\hline Pro & $\begin{array}{c}174.7 \pm \\
18.9\end{array}$ & $214.3 \pm 41.3$ & $\begin{array}{c}154.9 \pm \\
18.7\end{array}$ & 0.14 & $\begin{array}{c}144.1 \pm \\
9.7\end{array}$ & $\begin{array}{c}152.1 \pm \\
23.9\end{array}$ & $140.1 \pm 8.0$ & 0.56 & 0.16 \\
\hline Met & $19.4 \pm 1.4$ & $21.5 \pm 2.7$ & $18.3 \pm 1.6$ & 0.29 & $22.1 \pm 1.1$ & $22.4 \pm 2.3$ & $21.9 \pm 1.2$ & 0.86 & 0.13 \\
\hline Ala & $\begin{array}{c}272.2 \pm \\
17.8\end{array}$ & $274.9 \pm 33.3$ & $\begin{array}{c}270.9 \pm \\
21.6\end{array}$ & 0.92 & $\begin{array}{c}265.6 \pm \\
11.4\end{array}$ & $\begin{array}{c}261.2 \pm \\
21.0\end{array}$ & $\begin{array}{c}267.8 \pm \\
13.0\end{array}$ & 0.78 & 0.76 \\
\hline Leu & $\begin{array}{c}206.1 \pm \\
18.6\end{array}$ & $249.1 \pm 40.4$ & $\begin{array}{c}179.6 \pm \\
16.9\end{array}$ & 0.07 & $\begin{array}{c}175.7 \pm \\
8.6\end{array}$ & $\begin{array}{c}180.7 \pm \\
16.6\end{array}$ & $173.2 \pm 9.6$ & 0.68 & 0.15 \\
\hline Orn & $\begin{array}{c}110.4 \pm \\
6.2\end{array}$ & $111.4 \pm 12.7$ & $110.0 \pm 7.1$ & 0.92 & $92.2 \pm 5.6$ & $79.8 \pm 7.2$ & $98.5 \pm 6.9$ & 0.10 & 0.08 \\
\hline Gly & $\begin{array}{c}236.8 \pm \\
13.0 \\
\end{array}$ & $245.5 \pm 28.1$ & $\begin{array}{c}232.4 \pm \\
14.0 \\
\end{array}$ & 0.64 & $\begin{array}{c}237.1 \pm \\
11.0 \\
\end{array}$ & $\begin{array}{c}238.3 \pm \\
11.4 \\
\end{array}$ & $\begin{array}{c}236.5 \pm \\
15.0 \\
\end{array}$ & 0.94 & 0.98 \\
\hline
\end{tabular}

a: $p$ value from the comparison between PKU children females and males.

$\mathrm{b}$ : $p$ value from the comparison between normal children females and

males.

c: $\mathrm{p}$ value from the comparison between PKU children (total) and normal children (total).

The data in Table 1 were presented as mean \pm standard

deviation.

\section{Figures}

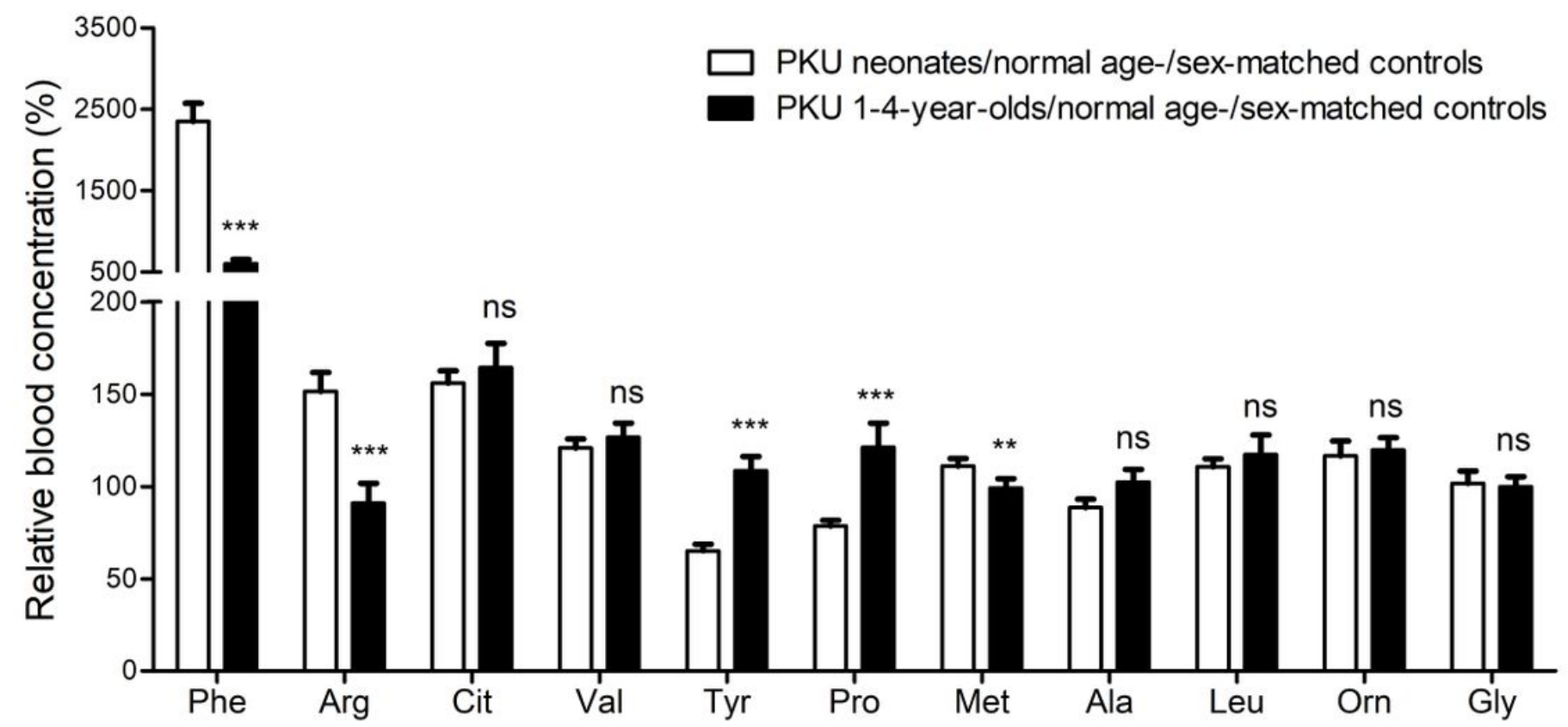

Figure 1 
Relative blood concentrations of Phe, Arg, Cit, Val, Tyr, Pro, Met, Ala, Leu, Orn, and Gly. Data grouped as mean \% amino acid concentration in PKU neonates relative to normal age-/sex-matched controls (white columns) and PKU 1-4 year-olds relative to normal age-/sex-matched controls (black columns). Error bars represent standard error of the mean. $* * *: p<0.001, * *: p<0.01$, ns: not statistically significant. 